\title{
High-temperature pervaporation performance of ceramic-supported polyimide membranes in the dehydration of alcohols
}

\author{
R. Kreiter \\ D.P. Wolfs \\ C.W.R. Engelen \\ H.M. van Veen \\ J.F. Vente
}

Published in Journal of Membrane Science 319 (2008), 126-132

DOI: 10.1016/j.memsci.2008.03.026 


\title{
High-temperature pervaporation performance of ceramic-supported polyimide membranes in the dehydration of alcohols
}

\author{
Robert Kreiter, Damian P. Wolfs, Charles W.R. Engelen, Henk M. van Veen, Jaap F. Vente* \\ Energy research Centre of the Netherlands, Energy Efficiency in Industry, P.O. Box 1, 1755 ZG Petten, The Netherlands
}

\section{A R T I C L E I N F O}

\section{Article history:}

Received 5 December 2007

Received in revised form 20 February 2008

Accepted 19 March 2008

Available online 27 March 2008

\section{Keywords:}

Membrane

Ceramic-supported polymer

Polyimide

Pervaporation

Dehydration

\begin{abstract}
A B S T R A C T
Ceramic-supported polymer (CSP) membranes were prepared based on Torlon, P84, and Matrimid. The dehydration performance of these membranes was determined by pervaporation of $n$-butanol/water mixtures $\left(95 / 5\right.$ wt\%) at $95^{\circ} \mathrm{C}$. Based on their performance P84 was selected for further testing. P84 membranes showed excellent separation performance in dehydration of $n$-butanol for at least 300 days. Different curing temperatures in the range of $70-300^{\circ} \mathrm{C}$ were used. The most significant flux difference was seen for a P84 membrane cured at $300^{\circ} \mathrm{C}$, compared to the lower temperatures. The separation performance of a P84 $\mathrm{CSP}$ membrane at $150^{\circ} \mathrm{C}$ showed water fluxes in the range of $1-6 \mathrm{~kg} / \mathrm{m}^{2} \mathrm{~h}$ and separation factors of at least 360. The membrane life-time in $n$-butanol/water mixtures ranges from 80 to 140 days at $150{ }^{\circ} \mathrm{C}$. No clear relation between curing temperature and membrane stability could be derived. Reasonable separation performance of a P84 CSP membrane in an ethanol/water mixture was demonstrated. Stable performance at $150{ }^{\circ} \mathrm{C}$ was observed for the dehydration of $t$-butanol up to at least 250 days.
\end{abstract}

(c) 2008 Elsevier B.V. All rights reserved.

\section{Introduction}

Molecular separation processes are responsible for an estimated $40 \%$ of the total energy consumption in the (petro)chemical industry worldwide. The main energy-consuming separation processes include dehydration of organic solvents, oxygen separation from air, olefin/paraffin separation, and hydrogen separation from several sources. These separations are currently performed using (cryogenic) distillation or adsorption-based techniques. The exergetic efficiency of these techniques is in general as low as $10 \%$ [1]. Separation using membrane technology is widely accepted as an energy-efficient alternative. Each of the above-mentioned applications has its own specific requirements, resulting in dedicated solutions in terms of appropriate membrane material, design of module and membrane geometry, sealing concept, and process design. For the profitable introduction into new markets, we believe that the membrane should be able to function at temperatures up to at least $150^{\circ} \mathrm{C}$ for several years.

A number of water selective materials have been proposed for application in pervaporation membranes over the years. The first class of materials is that of organic polymers. Polyvinyl alcohol (PVA) has been described as early as 1990 [2], and the performance can be improved through cross-linking [3]. Alternatives such

\footnotetext{
* Corresponding author. Tel.: +31 224 564949; fax: +31 224568615. E-mail address: vente@ecn.nl (J.F. Vente).
}

as polyamide-6 [4] and the polyimides Matrimid ${ }^{\circledR}$ [5], and P84 ${ }^{\circledR}$ [6-8] have been investigated. Microporous ceramic alternatives were presented for their expected higher chemical and thermal stability. Specific examples include amorphous networks of pure silica [9], methylated silica [10], silica/zirconia mixtures [11], and crystalline zeolites $[12,13]$. Commonly, the membrane performance is determined for the separation of water from iso-propanol or $n$ butanol at temperatures up to $100^{\circ} \mathrm{C}$. This temperature has been shown to be the maximum application temperature of commercial PVA membranes [14,15] and methylated silica [10]. To the best of our knowledge only one example of a membrane that is hydrothermally stable above $100^{\circ} \mathrm{C}$ has been reported in the open literature. This membrane type, developed in collaboration with our group, consists of an organic-inorganic hybrid silica-based material that can separate water from $n$-butanol at $150^{\circ} \mathrm{C}$ for a period of over 1 year [16].

Because of the high-temperature stability of high performance polymers, such as polyimides, we were interested in their longterm performance as water selective membrane materials at temperatures over $100^{\circ} \mathrm{C}$. To this end, we have selected materials with a high chemical and thermal stability and acceptable solubility, namely Matrimid ${ }^{\circledR}, \mathrm{P} 4^{\circledR}$, and the polyamide-imide Torlon ${ }^{\circledR}$ (Fig. 1). Polyimide membranes are commonly prepared in the form of hollow fibers with an inner and outer diameters ranging from 0.15 to $5 \mathrm{~mm}$ and from 0.3 to $8 \mathrm{~mm}$, respectively [5,17]. Limitations in the pervaporation performance can occur due to a pressure drop on the permeate side of the membrane as result 


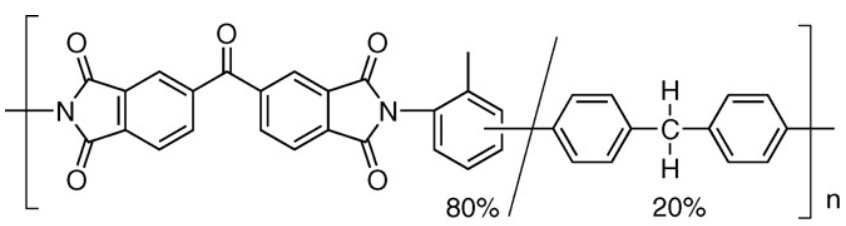

P84<smiles>CN1C(=O)c2ccc(C(=O)c3ccc4c(c3)C(=O)N(c3ccc(C5(C)CC(C)(C)c6ccccc65)cc3)C4=O)cc2C1=O</smiles>

Matrimid

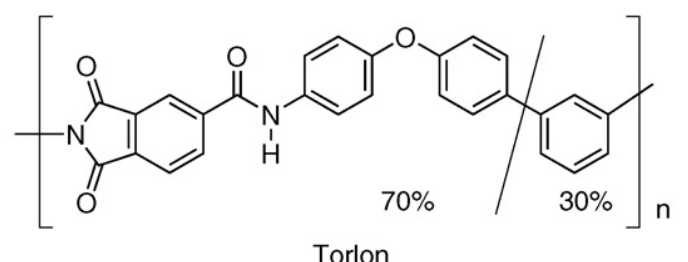

Fig. 1. Chemical structures of $P 84^{\circledast}$, Matrimid $^{\circledR}$, and Torlon ${ }^{\circledR}$.

the small inner diameter and the permeate side being located at the inside of the fiber [5]. This problem becomes especially important when scaling up to industrially sized units. Furthermore, the mechanical stability of hollow fibers could be an issue, especially at increased temperatures under relatively high-pressure drops. Microporous membranes are normally deposited as a thin layer $(\sim 100 \mathrm{~nm})$ on a mesoporous ceramic tubular support $[10,18]$ and do not suffer from these drawbacks. Therefore, we have chosen to make use of the concept of ceramic-supported polymer (CSP) membranes. This membrane concept is potentially suitable for the preparation of large quantities of membranes and is compatible with module and sealing designs developed for ceramic membranes.

In this report we will present the first results on the influence of polymer type, polymer concentration in the coating solution, and curing temperature on the long-term pervaporation performance (flux and separation factor) of an $n$-butanol/water mixture at temperatures up to $150{ }^{\circ} \mathrm{C}$. In addition, results for the high-temperature dehydration of ethanol and $t$-butanol are reported.

\section{Experimental}

\subsection{Membrane preparation}

Dense polymer top layers were prepared from solutions of the polyimides P84 ${ }^{\circledR}$ (High Performance Polymers Inc., Lenzing, Austria), Matrimid ${ }^{\circledR} 9725$ (Huntsman Advanced Materials, Basel, Switzerland), and the polyamide-imide Torlon $^{\circledR}$ AI-10 (Solvay Advanced Polymers, Greenville, USA). The polymer names are abbreviated hereafter as P84, Matrimid, and Torlon, respectively. The polymers were dissolved as received in $\mathrm{N}$-methylpyrrolidone (NMP, Merck) or $\gamma$-butyrolactone (Merck). Because of the similarity in performance of the membranes obtained from both solvents, only the results using NMP as a solvent are discussed here. Dip-coating techniques developed for ceramic membranes were applied, as described elsewhere [18]. Concentrations between 1 and 12 weight\% (wt\%) of polymer in the solvent were used for the dip-coating on tubular mesoporous ceramic supports. These supports consist of a commercially available extruded $\alpha$-alumina tube coated with two macroporous $\alpha$-alumina layers and a mesoporous $\gamma$-alumina top layer [18]. After dip-coating the tubes were transferred directly to a stove and cured in air at temperatures in the range of $70-300^{\circ} \mathrm{C}$ for $2 \mathrm{~h}$, with heating and cooling ramp rates of $1{ }^{\circ} \mathrm{C} / \mathrm{min}$. The thickness of the polymer layers was determined by pre- and post-test analyses of the membrane cross-section by means of Scanning Electron Microscopy using a Jeol 6330F SEM equipped with a Noran Voyager EDX.

\subsection{Solvent content in films}

To assess the content of NMP in the membranes after the curing procedure, differential thermal analysis and thermo-gravimetric analysis (DTA-TGA) were done on a Netzsch STA 409. All measurements were performed under air atmosphere on flat film polymer samples, prepared from $5 \mathrm{wt} \%$ polymer solutions. One measurement was done up to $600^{\circ} \mathrm{C}$ to investigate the solvent evaporation and polymer decomposition $\left(\mathrm{d} T / \mathrm{d} t=1^{\circ} \mathrm{C} / \mathrm{min}\right)$. For the other measurements ramp rates and dwell times were taken identical to those of the membrane preparation. After curing and cooling down the samples were heated again to $300^{\circ} \mathrm{C}\left(\mathrm{dT} / \mathrm{d} t=1^{\circ} \mathrm{C} / \mathrm{min}\right)$ and kept at this temperature until no solvent evaporation could be observed by weight loss.

\subsection{Pervaporation tests}

Long-term pervaporation measurements on the ceramicsupported polymer membranes, with a surface area of $\sim 40 \mathrm{~cm}^{2}$, were performed at $150^{\circ} \mathrm{C}$ in a continuous flow setup. The feed was pumped with a constant flow of $1000 \mathrm{l} / \mathrm{h}$ from a $50 \mathrm{l}$ storage vessel over six membrane modules that were aligned in series (Fig. 2). The retentate was fed back to the feed vessel. The performance of the membranes was determined individually at regular intervals with a feed mixture containing $5 \mathrm{wt} \%$ demineralized water in $n$ butanol, ethanol, or $t$-butanol (Merck P.A.). For additional testing glass setups were used at feed temperatures of $95^{\circ} \mathrm{C}$ and stainless steel autoclaves were used at $150^{\circ} \mathrm{C}$. These setups are operated batch-wise and the feed mixture is well stirred. During all the longevity tests the membranes were constantly kept on stream and the water content at the feed side was controlled to be $1-3 \mathrm{wt} \%$, while the permeate pressure was kept at 10 mbar. Measurements were done at $5 \mathrm{wt} \%$ of water in the feed (batch-wise processes) or the results were corrected for the feed composition (continuous flow setup). The permeate was cooled with liquid nitrogen to facilitate collection. The permeate composition was determined using the refraction index and the composition of the feed was determined by Karl Fischer titration. The separation factor, $\alpha$, is defined as

$\alpha=\frac{Y_{\mathrm{w}} / Y_{\mathrm{b}}}{X_{\mathrm{w}} / X_{\mathrm{b}}}$

where $Y$ and $X$ are the weight fractions of water $(\mathrm{w})$ and $n$-butanol (b) in the permeate and feed solutions, respectively.

\section{Results}

\subsection{Preparation}

The preparation of around 60 tubular CSP membranes with a total surface area of around $8000 \mathrm{~cm}^{2}$ proved to be relatively straightforward. Only a very limited number of attempts lead to a non-selective membrane. This happened for instance when the polymer concentration in the solvent was too low ( $\leq 1 \%$ for P84), 
(a)

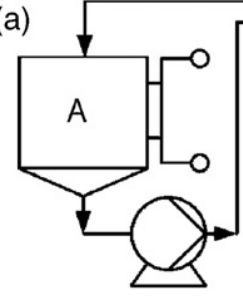

B

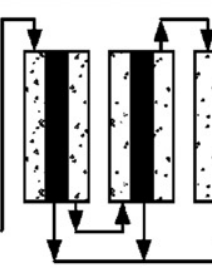

(n)

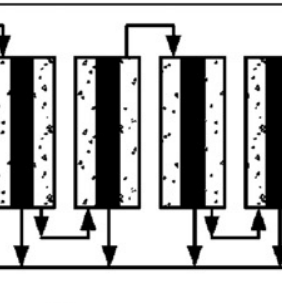

C

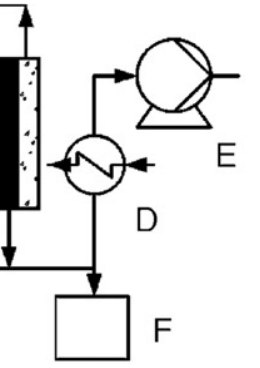
A: Storage vessel
B: Circulation pump
C: Membranes (black)

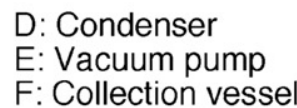

(b)

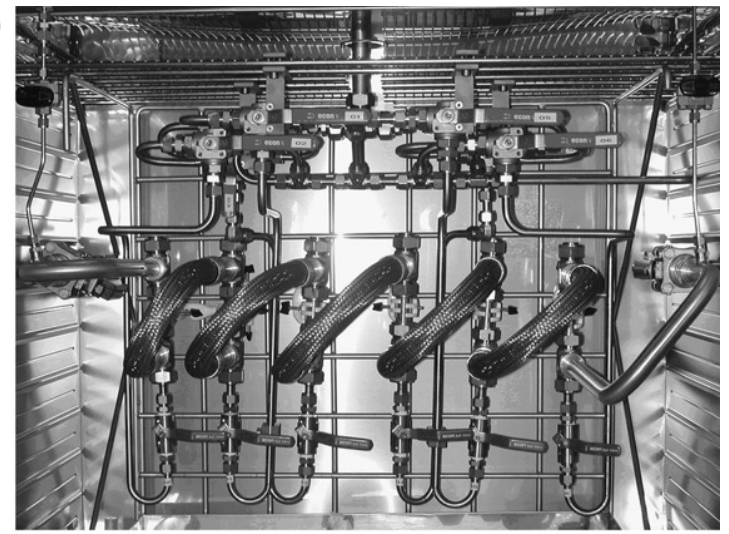

Fig. 2. (a) Schematic overview and picture (b) of continuous flow pervaporation setup used for longevity tests.

leading to imperfect coverage of the support. As proof for the gas tightness of the membrane the helium permeance was measured at room temperature. The values obtained were in all cases smaller than $3.0 \times 10^{-8} \mathrm{~mol} / \mathrm{m}^{2}$ Pa s, indicating the absence of defects.

Ceramic-supported polyimide layers were obtained with a mean layer thickness in the range of $0.2-10 \mu \mathrm{m}$, as determined with scanning electron microscope (SEM) measurements. The layer thickness depended mainly on the starting concentration of the polymer solution, whereas it was not significantly affected by the curing temperature. SEM images of cross-sections of these membranes revealed a layer thickness of about $7 \mu \mathrm{m}$ for a layer based on a $12 \mathrm{wt} \%$ solution of P84 in NMP and about $1 \mu \mathrm{m}$ for a layer based on a $5 \mathrm{wt} \%$ solution after curing at $70^{\circ} \mathrm{C}$ (Fig. 3 ).

\subsection{Solvent content}

DTA-TGA measurements were done on a P84 film prepared from a 2.5 -wt\% solution in NMP to estimate the residual solvent content after curing of the membranes. These measurements indicate a gradual weight loss from 90 to $350^{\circ} \mathrm{C}$, indicative for the evaporation of residual solvent (NMP). At $450^{\circ} \mathrm{C}$ a sharp decrease in weight sets in, which is accompanied by a strong exothermic DTA signal (Fig. 4a). This exothermic peak can be explained by oxidative decomposition of the polymer. Based on this measurement a program was setup to determine the residual solvent after different preparation methods. Samples from solutions of P84 in NMP were cured at 150,225 , and $300^{\circ} \mathrm{C}$ and cooled down, followed by the TGA program (Fig. 4b). For the samples cured at 150 and $225^{\circ} \mathrm{C}$ a significant weight loss of 10 and 5\%, respectively, is observed during this program. During the dwell at $300^{\circ} \mathrm{C}$ the weight loss continues for these samples. These data indicate that a significant amount of NMP is still present in the samples cured. For the sample cured at $300^{\circ} \mathrm{C}$ no additional weight loss was observed during this program.

\subsection{Pervaporation performance at $95^{\circ} \mathrm{C}$}

The pervaporation performance of the different CSP membranes was compared at $95^{\circ} \mathrm{C}$ in an $n$-butanol/water mixture (Fig. 5). The Matrimid membrane showed a slightly higher water flux than the Torlon and P84 membranes. However, the water content of the permeate was only around $75-80 w t \%(\alpha=57-76)$ for Matrimid, whereas the Torlon and P84 membranes had initial water contents in the permeate of over $95 \mathrm{wt} \%(\alpha>361)$. For the Torlon membrane, a clear decrease in separation performance is noted in the course of 120 days of continuous testing. After this period the water content in the permeate is only $90 \mathrm{wt} \%$. Despite the decrease in separation factor, the water flux of this Torlon membrane is stable during the measurement period. The P84 membrane clearly has the highest water content in the permeate stream of these three supported polymer membranes (around $98 \mathrm{wt} \%, \alpha=931$ ).

Based on this information we selected P84 for further optimization in a detailed screening. The effect of the curing temperature

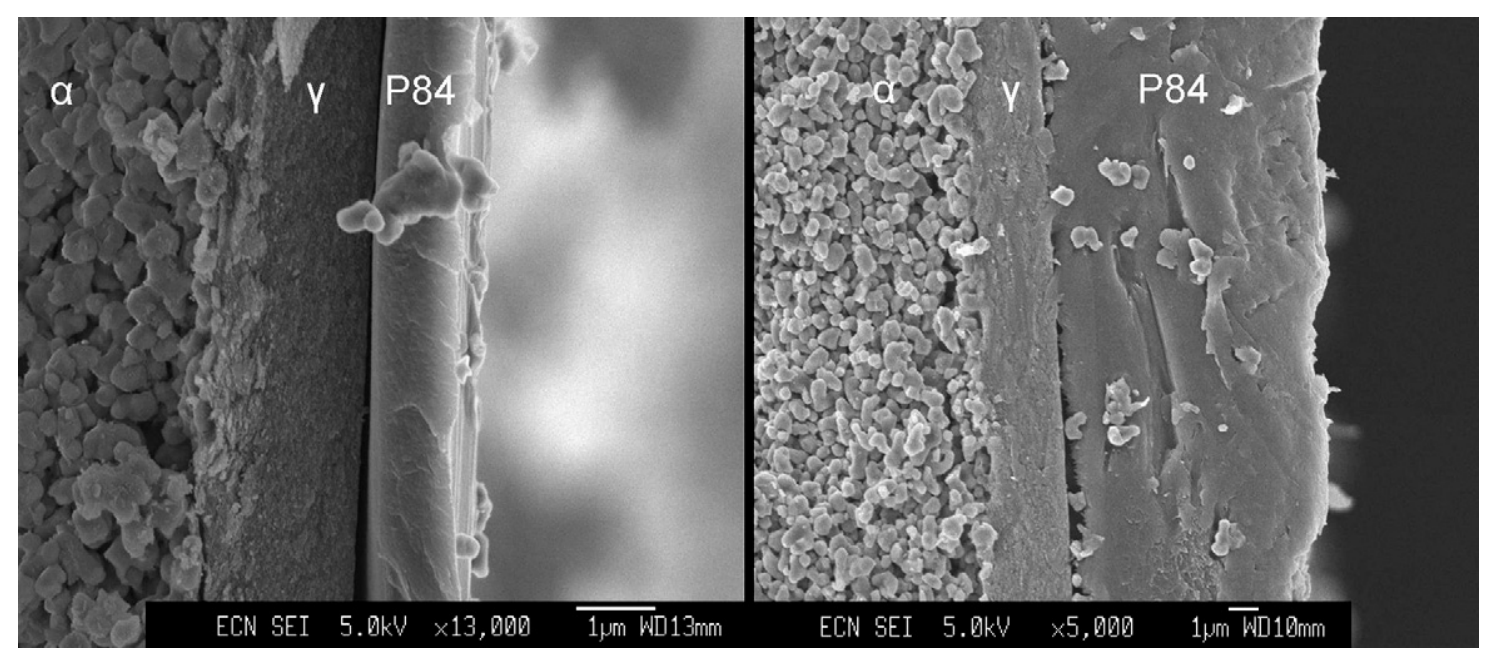

Fig. 3. SEM images of ceramic-supported P84 membranes based on 5 wt $\%$ (left) and 12 wt $\%$ (right) solutions at different magnifications; $\alpha$-, $\gamma$-alumina, and P84 layer indicated. 

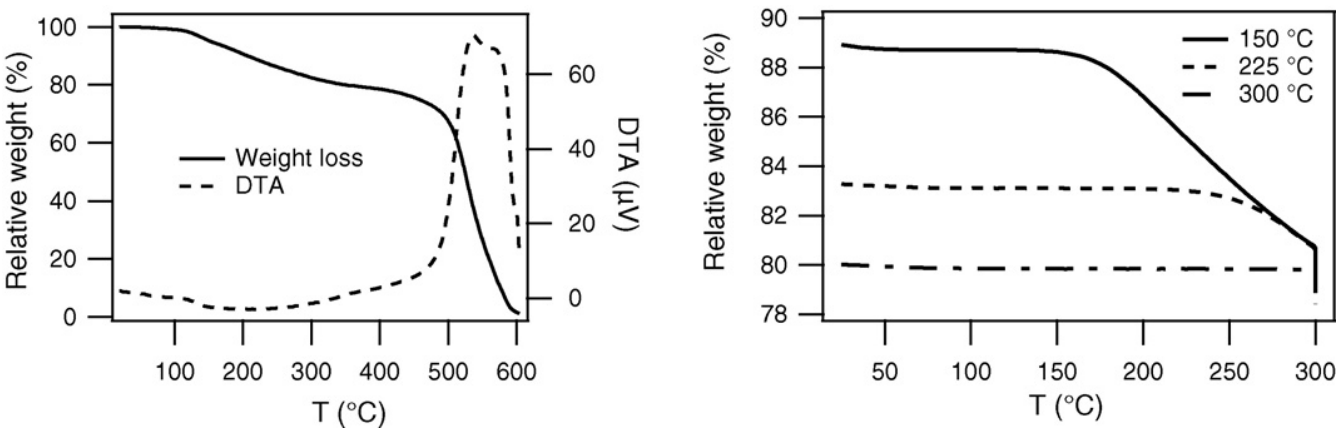

Fig. 4. (a) DTA-TGA plot of P84 film, casted from $2.5 \mathrm{wt} \%$ solution in NMP and (b) relative weight of P84 samples during ramp to and dwell at $300{ }^{\circ} \mathrm{C}$, after curing at 150,225 , and $300^{\circ} \mathrm{C}$.
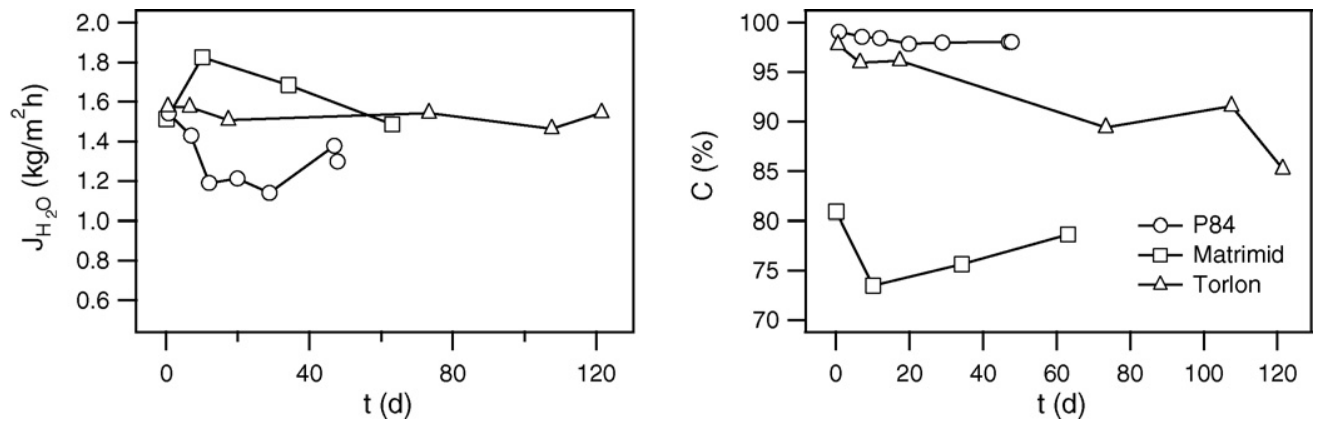

Fig. 5. (a) Water flux and water concentration in permeate (b) against time (in days) for P84, Matrimid, and Torlon membranes based on 5 wt\% solutions in NMP, cured at $200^{\circ} \mathrm{C}$. Conditions: 5 wt $\%$ water in $n$-butanol at $95^{\circ} \mathrm{C}$.

was investigated using P84 membranes based on $5 \mathrm{wt} \%$ solutions in NMP with curing treatments at $70,100,150,200$, and $300^{\circ} \mathrm{C}$ (Fig. 6). The long-term behavior of these membranes indicates that the water fluxes decrease slightly during the first about 20 days for the membranes cured in the range of $70-200^{\circ} \mathrm{C}$. All of these fluxes are in the range of $1-2 \mathrm{~kg} / \mathrm{m}^{2} \mathrm{~h}$ after an initial stabilization period. The water flux obtained for the membrane cured at $200^{\circ} \mathrm{C}$ is the lowest of the four membranes in this range. The water flux of the membrane cured at $300^{\circ} \mathrm{C}$ is significantly lower and varies between 350 and $650 \mathrm{~g} / \mathrm{m}^{2} \mathrm{~h}$ over a period of 270 days. Overall, the water content of the permeate stream increases slightly with higher curing temperatures. The best performance results were obtained for membranes cured in the temperature range of $150-300^{\circ} \mathrm{C}$. As an example, the membrane cured at $300^{\circ} \mathrm{C}$ shows relatively stable behaviour with a water content in the permeate of over $95 \mathrm{wt} \%$ up to 235 days (not shown in the graph). After this period it strongly decreases, indicative for the breakdown of the membrane.

A comparison of the water flux against the weight percentage of polymer in the preparation solution was made, using membranes

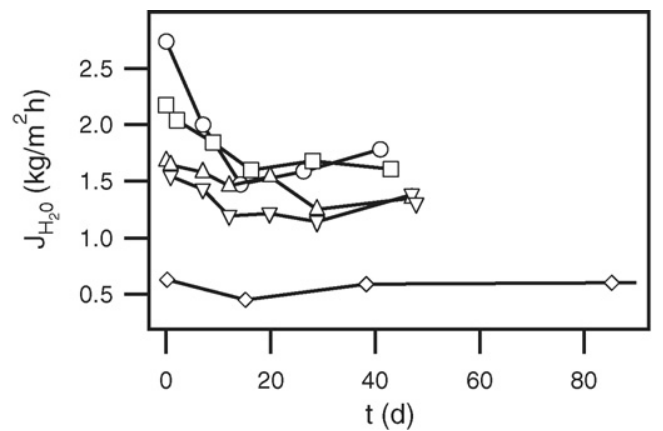

based on 2.5, 5, and $12 \mathrm{wt} \%$ of P84 cured at $70^{\circ} \mathrm{C}$ (Fig. 7). The testing conditions were $95^{\circ} \mathrm{C}, 5 \mathrm{wt} \%$ water in $n$-butanol and a permeate pressure of 10 mbar. These results show that the flux decreases with increasing weight percentage of polymer solution. This relates well with the observed increase in layer thickness with increasing polymer concentration. Importantly, the water content of the permeate stream is comparable and over $95 \mathrm{wt} \%$ for all three polymer concentrations. Moreover, for the membranes based on 2.5 and $5 \mathrm{wt} \%$ concentrations the performance was measured for a period of 280 days and remained nearly constant. After a decrease in flux during the first 20 days of operation, the flux increased slightly for these membranes over the remaining running time. After 280 days, the selectivity of the membrane based on $2.5 \mathrm{wt} \%$ P84 strongly declines due to a sharp increase of the $n$-butanol flux.

\subsection{Pervaporation performance at $150^{\circ} \mathrm{C}$}

Pervaporation measurements at $150^{\circ} \mathrm{C}$ using a water $/ n$-butanol feed mixture were performed to estimate the potential for these

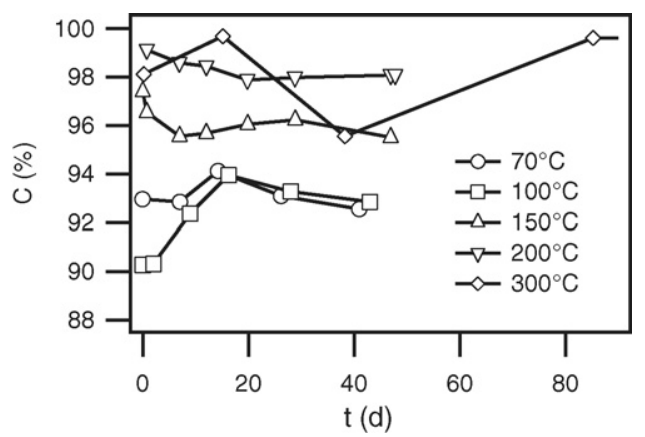

Fig. 6. Influence of curing temperature on water flux (a) and water concentration in permeate (b) against time (in days) for P84 membranes based on 5 wt\% solution in NMP. Conditions: $5 \mathrm{wt} \%$ water in $n$-butanol at $95^{\circ} \mathrm{C}$. 

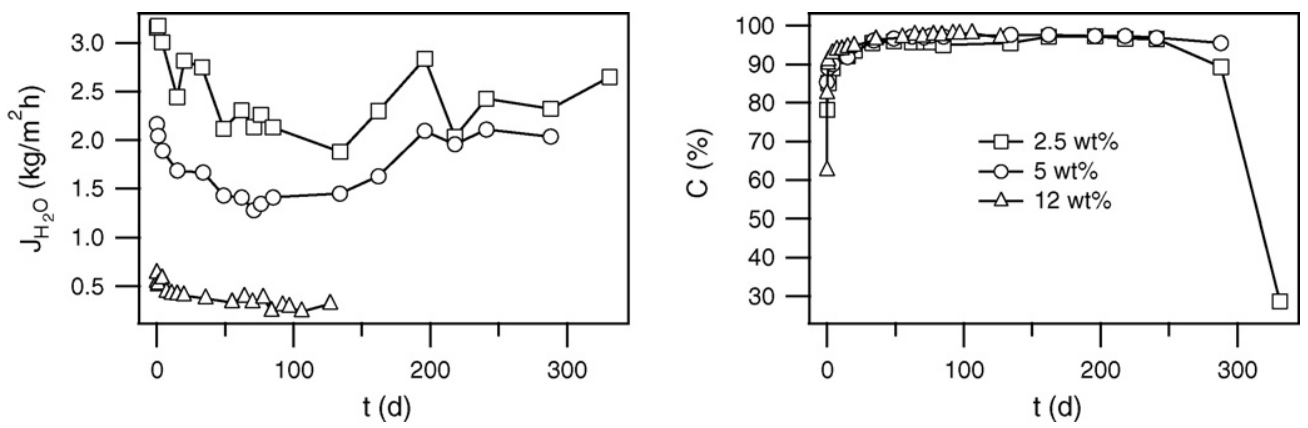

Fig. 7. Influence of P84 concentration in dip-coating $\left(2.5,5,12\right.$ wt $\%$ ) on water flux (a) and water concentration in permeate (b). Conditions: 5 wt $\%$ water in $n$-butanol at $95{ }^{\circ} \mathrm{C}$.
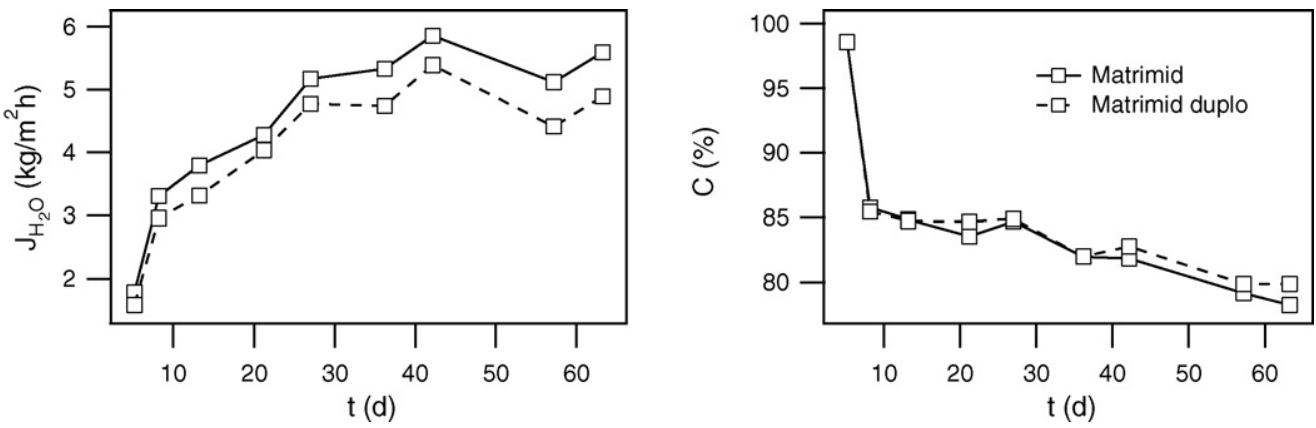

Fig. 8. (a) Water flux and water concentration in permeate (b) against time (in days) for two Matrimid membranes based on 10 wt $\%$ solutions in NMP, cured at $300{ }^{\circ} \mathrm{C}$. Conditions: $5 \mathrm{wt} \%$ water in $n$-butanol at $150^{\circ} \mathrm{C}$.

CSP membranes in the higher temperature range. At this temperature Matrimid membranes have an initial water content of over $95 \mathrm{wt} \%$ in the permeate. However, for all of the Matrimid membranes the water content drops to $70 \mathrm{wt} \%$ in the course of 10 days. In addition, the water and $n$-butanol fluxes increase steadily over the whole measurement period of up to 70 days. The performance of the Matrimid membranes was very reproducible and all membranes based on this polymer show a similar rapid decrease in selectivity. As an example, the performance of Matrimid membranes based on $10 \mathrm{wt} \%$ polymer solution that were cured at $300^{\circ} \mathrm{C}$ is shown (Fig. 8). Parallel small fluctuations in performance of both membranes are observed because of small fluctuations in water concentration of the feed in the continuous flow setup (Fig. 8). These membranes were tested in the same test run and the similarity of their performance can be attributed to reproducible preparation of the membranes.

For the P84 membranes the water content in the permeate stream is over $95 \mathrm{wt} \%$ in all cases for the first 80-100 days of operation. Similar to the measurements at $95^{\circ} \mathrm{C}$ the membranes prepared from 5 to $12 \mathrm{wt} \%$ solutions of P84 have lower fluxes compared to those prepared from a $2.5 \mathrm{wt} \%$ solution. In addition the initial water flux observed for a membrane cured at $300^{\circ} \mathrm{C}$ is lower than for those cured at lower temperatures. Because of their superior fluxes, membranes based on $2.5 \mathrm{wt} \%$ solutions were selected for further experiments. For all of the membranes a gradual increase of the water flux over the complete measurement period was observed. This effect was more dramatic for the membranes prepared from lower concentrations of P84. Different temperatures of heat treatment $\left(150,225\right.$, and $\left.300^{\circ} \mathrm{C}\right)$ do not have a significant effect on the rate of the water flux increase. After 80-140 days of operation the $n$-butanol fluxes increases to such an extent that the selectivity drops (Fig. 9). The separation experiments were stopped when this occurred.

We investigated the influence of the long-term hightemperature pervaporation conditions on the membrane layer with SEM. A membrane based on 12 wt\% of P84 in NMP was tested in an $n$-butanol/water $95 / 5 \mathrm{wt} \%$ mixture at temperatures ranging from 110 to $150^{\circ} \mathrm{C}$ during a total running time of 250 days. The
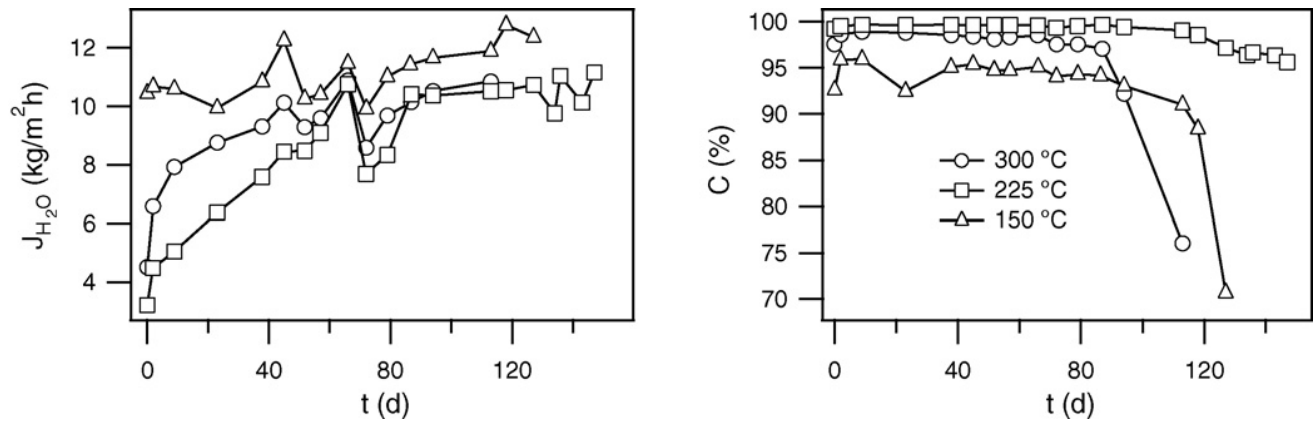

Fig. 9. Influence of curing temperature $\left(150,225,300^{\circ} \mathrm{C}\right)$ on water flux (a) and water concentration in the permeate (b) of P84 membranes prepared from 2.5 wt\% solution. Conditions: 5 wt $\%$ water in $n$-butanol, $150^{\circ} \mathrm{C}$. 

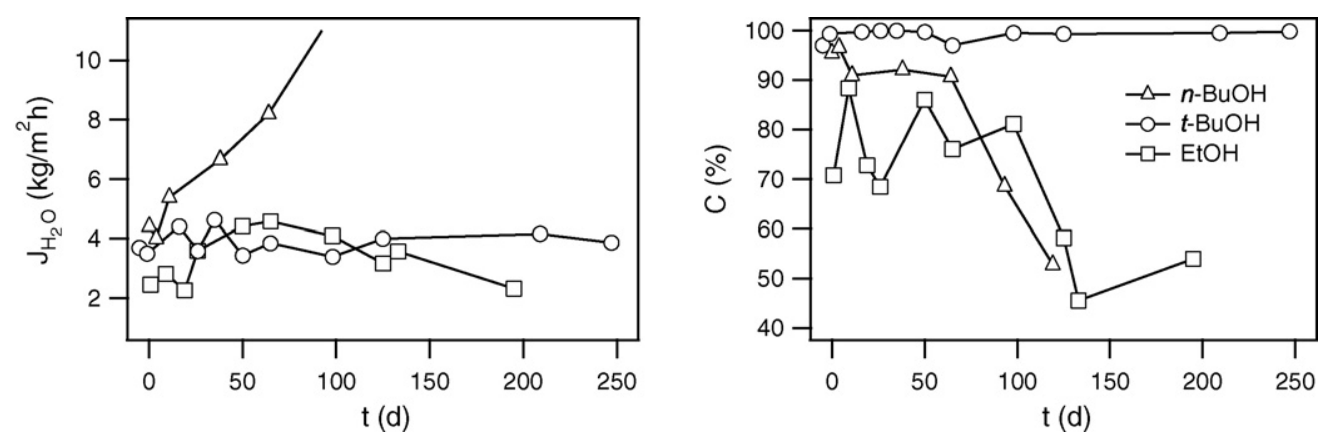

Fig. 10. Influence of pervaporation feed mixture on performance of P84 membrane. Conditions: $150{ }^{\circ} \mathrm{C}, 5 \mathrm{wt} \%$ water in $n$-butanol, $t$-butanol, or ethanol.

estimates of the layer thickness using SEM indicate that for this membrane the initial thickness of about $9 \mu \mathrm{m}$ is reduced to $120 \mathrm{~nm}$ after this test. Apparently, most of the membrane material is lost during the experiment.

The comparison of the pervaporation results using a feed mixture of $5 \mathrm{wt} \%$ water in either $n$-butanol, $t$-butanol, or ethanol at $150{ }^{\circ} \mathrm{C}$ lead to unexpected results (Fig. 10). Despite the long-term stability of P84 membranes in the dehydration of $n$-butanol at $95^{\circ} \mathrm{C}$, an increase of the flux over a period of 90 days was observed at $150^{\circ} \mathrm{C}$. After this time period a drop of the water content in the permeate stream was observed for this separation. For the dehydration of ethanol the water flux fluctuated around an average value of $3 \mathrm{~kg} / \mathrm{m}^{2} \mathrm{~h}$ over a period of 200 days. The water content in the permeate ranged from $90 \%$ initially to $50 \%$ after 200 days. In contrast, for $t$-butanol a completely stable behavior of the water flux and the water concentration in the permeate was observed for a measurement time of 250 days at $150^{\circ} \mathrm{C}$. The water flux was stable at around $4 \mathrm{~kg} / \mathrm{m}^{2} \mathrm{~h}$ with a water content in the permeate stream of over $99 \mathrm{wt} \%(\alpha>1881)$.

\section{Discussion and conclusions}

Based on these pervaporation results it appears that the separation factors of obtained for ceramic-supported P84 membranes are much higher than those of Matrimid and Torlon membranes. The initial water fluxes obtained with these P84 membranes are in the range of $1-6 \mathrm{~kg} / \mathrm{m}^{2} \mathrm{~h}$ and are among the highest reported in literature (see e.g. $[6,8,21]$ ). Therefore we conclude that of these three polymer types P84 is the most suitable material for the pervaporation of $n$-butanol/water mixtures. The higher separation factor obtained for P84 as compared to Matrimid can be related to the higher fractional free volume of Matrimid [22]. For Torlon the initial performance is comparable to P84, which is in line with their comparable free volume. However, the separation factor of the Torlon membrane rapidly declines, whereas the P84 membrane shows stable performance. We propose that the polyamide groups in Torlon are prone to hydrolysis, leading to structural changes and eventually to breakdown of the membrane. The stable longterm pervaporation performance of the P84 CSP membranes in $95 / 5 \mathrm{wt} \% \mathrm{n}$-butanol/water mixtures at $95^{\circ} \mathrm{C}$ is unprecedented in literature. Measurement times of $80-100$ days could be achieved easily without noticeable degradation of the membrane. A number of these membranes were tested for longer periods and performed well even up to at least 300 days. Only one membrane based on the lowest polymer concentration (the thinnest layer) broke down after about 300 days of testing. Curing temperatures of 200 and $300^{\circ} \mathrm{C}$ clearly lead to lower water fluxes and slightly improved separation factors. Based on the TGA results for free standing films, this can be attributed to a lower residual solvent content after these curing treatments. Removal of the residual NMP presumably leads to further densification of the polymer film and thus to lower water fluxes. It is clear that depending on the specific application, the water flux and separation factors can be tuned within reasonable limits. The separation factors can be increased up to 1881 (99 wt\% water in the permeate), at the expense of the water flux.

During separation measurements at $150^{\circ} \mathrm{C}$ degradation of the membranes in water $/ n$-butanol mixtures occurs at a higher rate. All membranes exhibit a gradual increase in both water and $n$-butanol flux, eventually leading to loss of selectivity. For the Matrimid membranes the water and $n$-butanol fluxes increase rapidly during the first 25 days of operation. Consequently, the water content in the permeate drops to a disappointing $85 \%$ in this period. This is similar to the performance of the Matrimid membrane observed at $95^{\circ} \mathrm{C}$. Most of the P84 membranes break down after $80-120$ days of operation at $150^{\circ} \mathrm{C}$ in $n$-butanol/water. Still, the stability of the P84 membranes is much higher than that of the Matrimid membranes. Interestingly, a P84 membrane is stable up to at least 250 days in a mixture of $95 / 5 \mathrm{wt} \% t$-butanol/water. At the moment we do not have an explanation for this apparent difference in the two alcohol/water mixtures. For example, the Hansen solubility parameters [23] for $n$-butanol and $t$-butanol are very similar and do not explain the large difference in performance.

From the post-test analysis results for the separation of $n$ butanol/water it is clear that loss of membrane material occurs during the measuring time. The SEM micrographs of the membrane layer before and after testing are featureless. Therefore, we conclude that morphology changes due to phase changes at the membrane surface are not taking place. At this moment is unclear if either degradation or dissolution of the polymer chains is responsible for the loss of material. Based on the available literature on polyimide degradation $[19,20]$, we propose that hydrolysis of polyimide group results in gradual breakdown of the polymer chains. Based on the rapid degradation of Matrimid at $150^{\circ} \mathrm{C}$, hydrolysis of this polymer occurs at a much higher rate than hydrolysis of P84. Currently, we are investigating this effect in more detail and are looking into modifications of the CSP membranes to arrive at higher stabilities.

In general, the pervaporation performance of these membranes is highly reproducible, indicating the suitability of this approach for larger scale application. Furthermore, we have demonstrated that several tens of tubular ceramic-supported polyimide membranes can be prepared quite readily. The results obtained for high-temperature dehydration using these CSP membranes are especially promising. To the best of our knowledge, this long-term behavior of polyimide membranes in pervaporation at temperatures above $100^{\circ} \mathrm{C}$ is demonstrated for the first time. It is clear that under these industrially relevant conditions the long-term stabil- 
ity of P84 and Matrimid membranes in $n$-butanol/water is limited. However, the stability of the P84 membrane in the dehydration of $t$-butanol is very high, which opens the way for pre-commercial testing of this application. Therefore, we are aiming at the application of such polyimide membranes on a larger scale of $1 \mathrm{~m}^{2}$, using a previously developed pilot scale separation unit.

\section{References}

[1] J.L. Humphrey, A.F. Seibert, Separation technologies: an opportunity for energy savings, Chem. Eng. Prog. 92 (1992) 32.

[2] C.M. Hu, W.Y. Chiang, Separation of liquid mixtures by using polyme membranes. II. Water-alcohol separation by pervaporation through PVA membranes, Angew. Makromol. Chem. 179 (1990) 157

[3] J.W. Rhim, C.K. Yeom, S.W. Kim, Modification of poly(vinyl alcohol) membranes using sulfur-succinic acid and its application to pervaporation separation of water-alcohol mixtures, J. Appl. Polym. Sci. 68 (1998) 1717.

[4] W. Kujawski, M. Waczynsky, M. Lasota, Pervaporation properties of dense polyamide-6 membranes in separation of water-ethanol mixtures, Sep. Sci. Technol. 31 (1996) 953.

[5] F. Zhou, W.J. Koros, Pervaporation using hollow fiber membranes for dehydrating acetic acid and water mixtures, Ind. Eng. Chem. Res. 45 (2006) 1787.

[6] X. Qiao, T.S. Chung, Fundamental characteristics of sorption, swelling and permeation of P84 co-polyimide membranes for pervaporation dehydration of alcohols, Ind. Eng. Chem. Res. 44 (2005) 8938

[7] R. Liu, X. Qiao, T.S. Chung, The development of high performance P84 copolyimide hollow fibres for pervaporation dehydration of isopropanol, Chem. Eng. Sci. 60 (2005) 6674.

[8] X. Qiao, T.S. Chung, K.P. Pramoda, Fabrication and characterization of BTDATDI/MDI (P84) co-polyimide membranes for the pervaporation dehydration of isopropanol, J. Membr. Sci. 264 (2005) 176.

[9] A.W. Verkerk, P. van Male, M.A.G. Vorstman, J.T.F. Keurentjes, Description of dehydration performance of amorphous silica pervaporation membranes, J. Membr. Sci. 193 (2001) 227.
[10] J. Campaniello, C.W.R. Engelen, W.G. Haije, P.P.A.C. Pex, J.F. Vente, Long term pervaporation performance of microporous methylated silica membranes, Chem. Commun. (2004) 834

[11] M. Asaeda, Y. Sakou, J. Yang, K. Shimasaki, Stability and performance of porous silica-zirconia composite membranes for pervaporation of aqueous organic solutions, J. Membr. Sci. 209 (2002) 163.

[12] M. Noack, P. Koelsch, J. Caro, M. Schneider, P. Toussaint, I. Sieber, MFI membranes of different $\mathrm{Si} / \mathrm{Al}$ ratios for pervaporation and steam permeation, Micropor. Mesopor. Mater. 35-36 (2000) 263.

[13] S. Sommer, T. Melin, Influence of operation parameters on the separation of mixtures by pervaporation and vapor permeation with inorganic membranes. Part 1. Dehydration of solvents, Chem. Eng. Sci. 60 (2005) 4509.

[14] S.P. Nunes, K.V. Peinemann, Membrane Technology in the Chemical Industry, Wiley-VCH, Weinheim, 2001.

[15] A. Jonquieres, R. Clement, P. Lochon, J. Neel, M. Dresch, B. Chretien, Industrial state-of-the-art of pervaporation and vapour permeation in the western countries, J. Membr. Sci. 206 (2002) 87.

[16] H.L. Castricum, A. Sah, R. Kreiter, D.H.A. Blank, J.F. Vente, J.E. ten Elshof, Hybrid ceramic nanosieves: stabilizing nanopores with organic links, Chem. Commun. (2008) 1103

[17] J.N. Barsema, G.C. Kapantaidakis, N.F.A. van der Vegt, G.H. Koops, M. Wessling Preparation and characterisation of highly selective dense and hollow fiber asymmetric membranes based on BTDA-TDI/MDI co-polyimide, J. Membr. Sci. $216(2003) 195$

[18] B.C. Bonekamp, A. van Horssen, L.A. Correia, J.F. Vente, W.G. Haije, Macroporous support coatings for molecular separation membranes having a minimum defect density, J. Membr. Sci. 278 (2006) 349.

[19] C.A. Pryde, Polyimide hydrolysis; measurement by Fourier transform-IR spectroscopy, ACS Symp. Ser. 407 (1989) 57.

[20] R. Delasi, J. Russell, Aqueous degradation of polyimides, J. Appl. Polym. Sci. 15 (1971) 2965

[21] T.S. Chung, W.F. Guo, Y. Liu, Enhanced Matrimid membranes for pervaporation by homogenous blends with polybenzimidazole (PBI), J. Membr. Sci. 271 (2006) 221.

[22] A. Bos, I.G.M. Punt, M. Wessling, H. Strathmann, $\mathrm{CO}_{2}$-induced plasticization phenomena in glassy polymers, J. Membr. Sci. 155 (1999) 67.

[23] A.F.M. Barton, Handbook of Solubility Parameters, CRC Press, 1983, pp. 153-157. 